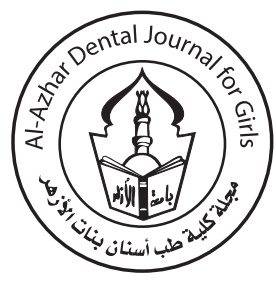

\title{
Evaluation of the Effect of Fluoride Application on Periodontal Health during Orthodontic Treatment (A Clinical Study)
}

\author{
Maha M. Seyam ${ }^{1 *}$, Samir A. Ibrahim², Abeer S. Gawish ${ }^{3}$, Mohamed A. Sherif ${ }^{4}$
}

Codex : 20/21.01

azhardentj@azhar.edu.eg

http://adjg.journals.ekb.eg

DOI: $10.21608 /$ adjg.2021.14177.1182

Pediatric Dentistry \& Orthodontics ( Pediatric Dentistry, Orthodontics)

\section{KEYWORDS}

Fluoride, Interleukin- 1beta,

Orthodontic, Periodontal Health.

\begin{abstract}
Purpose: This study was carried out to evaluate the effectiveness of different fluoride applications on periodontal health (clinical and microbiological) during orthodontic treatment with fixed appliance. Patients \& Methods: The study groups were designed randomly into three equal groups using the same type of (fluoride-free) toothpaste. Group I used PERIOMED contains stannous fluoride mouthwash, group II used LISTERINE ${ }^{\circledR}$ contains sodium fluoride Mouthwash and the control group used distilled water. All patients were put onto the recall schedule at zero, $7^{\text {th }}, 14$ and 28 days Samples were collected for detection of the interleukin-1 beta level, determination of reduction in microbial count and assessment of the following clinical parameters: pocket depth, plaque index, and gingival index. They were recorded at these time intervals mentioned. Following Orthodontic treatment for all patients, Interleukin- 1 beta and Colony Forming Units (CFUs) were measured. Results: interleukin-1beta level and bacterial count were high at the onset of periodontal inflammation at the same range with no significant differences between the studied groups. At the end of the study, group I and group II showed a marked decrease in the interleukin-1beta level and bacterial count compared to the control group, and there was a statistically nonsignificant difference between group I \& II. Conclusion: Stannous fluoride mouthwash showed the best results in the level of IL-1 $\beta$, since in the reduction of the bacterial count also includes improving in the clinical parameters (PD, PI, GI) compared with the other samples of the study.
\end{abstract}

- Paper extracted from Master thesis titled "Evaluation of the Effect of Fluoride Application on Periodontal Health during Orthodontic Treatment (A Clinical Study)"

1. B.D.S 2012G Oral and Dental Medicine - Sinai University, Egypt

2. Professor of Orthodontic Department, Faculty of Dental Medicine for Girls, Al-Azhar University, Cairo, Egypt.

3. Professor of Oral Medicine, Periodontology, Diagnosis, and Radiology, Faculty of Dental Medicine for Girls, Al-Azhar University, Cairo, Egypt.

4. Professor of Microbiology, and Immunology, Faculty of Medicine, Cairo, Boys' branch, Al-Azhar University, Cairo, Egypt.

* Corresponding author email: mohamed.deabs@yahoo.com 


\section{INTRODUCTION}

Fixed orthodontic treatment is the most common technique for the treatment of malocclusion. Maintaining good or acceptable oral hygiene is a difficult task for the patient undergoing orthodontic treatment with fixed appliances ${ }^{(1,2)}$.

The fixed component of the orthodontic appliance, such as brackets, bands and fixed retentions, can complicate optimal hygiene and this can cause the accumulation of dental plaque and gingival inflammation ${ }^{(3,4)}$. Dental plaque is the main factor for dental caries and periodontal disease. ${ }^{(5,6)}$ Rough surfaces and the presence of different spaces around the bracket bases are critical sites for the accumulation of bacterial plaque ${ }^{(1)}$.

It is difficult to effectively educate, train and encourage patients to reduce plaque solely by mechanical means of plaque removal. It requires time, motivation and manual dexterity.

Gingivitis is caused by bacterial plaque colonization on tooth surfaces and subsequent invasion of the micro-organisms into the gingival sulcus ${ }^{(7)}$.

An increase in pathogenic periodontal bacteria and a subsequent increase in inflammation around orthodontic bands and brackets have been observed compared to unbanded or joined teeth ${ }^{(2,8)}$. Gingivitis and gingival enlargement are the result of inflammation response to plaque microbiota and its product inflammatory mediators because of increased vascular permeability and dilation ${ }^{(9)}$.

The exudative fluid and protein swell the tissue and an influx of inflammatory cells occurs to the connective tissue sub adjacent to the junctional epithelium. Periodontal pathogens cause signals in resident gingival cells or immune cells that infiltrate gingival tissues, resulting in an immune response (10). Cytokines in inflamed periodontal tissues have been cited as of major importance in the progression of periodontal disease ${ }^{(11)}$.
The local production of interleukin (IL) -1B in the gingival crevicular fluid has been shown to increase with increasing inflammation ${ }^{(10,12)}$, therefore IL-1B is a reliable marker for the degree of gingival inflammation. The health status of periodontal tissues is determined by using the periodontal index according to the criteria of the plaque index system and the gingival index system and the gingival bleeding index system followed by an evaluation of the probing pocket depth.

The benefits of fluoride are well known; it is lethal to bacteria and aids in enamel remineralization. It forms fluorapatite, which is more acid-resistant than hydroxyapatite fluorides. The desensitization effects come from its ability to block the tubules and slow down the fluid causing sensitivity (13). Toothpaste containing amine fluoride (AMF), sodium fluoride (Naf) and stannous fluoride has been documented in several studies ${ }^{(14,15)}$ stannous fluoride also has a known plaque inhibiting effect and can inhibit bacterial metabolism, reduce both plaque and delayed gingivitis. Fluoride mouthwashes significantly reduce the degree of decalcification enamel and gingival inflammation during orthodontic treatment ${ }^{(16)}$. Therefore, the present study aimed to evaluate the effectiveness of different fluoride applications on periodontal health during orthodontic treatment with fixed appliance.

\section{SUBJECTS AND METHODS}

The study groups were designed randomly into three equal groups using the same type of (fluoridefree) toothpaste. Group I used PERIOMED contains stannous fluoride mouthwash, group II used LISTERINE $^{\circledR}$ contains sodium fluoride Mouthwash and the control group used distilled water.

\section{Criteria for patient selection:}

All patients were indicated for orthodontic treatment with fixed appliance. The study inclusion criteria were: Patients were free from any systematic diseases (according to the Cornell Medical Index) 
(17). Patients did not receive anti-inflammatory drugs or antibiotics in the previous 6 months and during the study period. The patient did not receive previous orthodontic treatment. The patients should not reveal any sign of periodontal destruction either clinically or radiographic examination. Patients have a full set of permanent teeth except third molar teeth.

\section{Discontinuation criteria:}

Uncooperative patients, frequent missing appointments, frequent broken appliance. No following the patient instructions concerning orthodontic and surgical steps, patients who did not follow orthodontic or surgical instructions.

This study has approved by the ethical committee of the Faculty of Dental Medicine of Al-Azhar University, Cairo, Egypt. (NO. ORTHO- 108- 3)

The patients and /or guardians were fully informed about the procedure and informed written consents (Appendix II) were signed by them before starting the study work. Repeated oral hygiene instructions relating to correct using of the selected toothpaste, mouthwashes, dental floss, and interdentally brush was given to patients to inform them how to perform effective tooth cleaning in the presence of the orthodontic appliance. All patients put onto the recall schedule at zero, $7^{\text {th }}, 14$ and 28 days. Samples were collected for detection of the interleukin-1 beta level, determination of reduction in microbial count and assessment of the following clinical parameters pocket depth, plaque index, and gingival index. They were recorded at these time intervals mentioned.

Following Orthodontic treatment for all patients was done using direct bonding (Green Glu bonding composite) for the upper and lower teeth using Roth prescription bracket. Leveling and alignment using sequence of (wire 0.012 or 0.014 -inch NiTi), (wire 0.016 -inch NiTi), ending with (wire $0.016 \times 0.022$ inch NiTi) and elastic ligature ties. Interleukin- 1 beta was measured in GCF using the EnzymeLinked Immunosorbent Assay technique (ELISA test) (Fig.1). The number of Colony Forming Units (CFUs) for measuring the microbial count was counted and calculated according to this equation: Number of colonies $(\mathrm{CFUs})=$ bacteria $\mathrm{X} \mathrm{ml}$ dilution $\mathrm{X}$ amount plated.

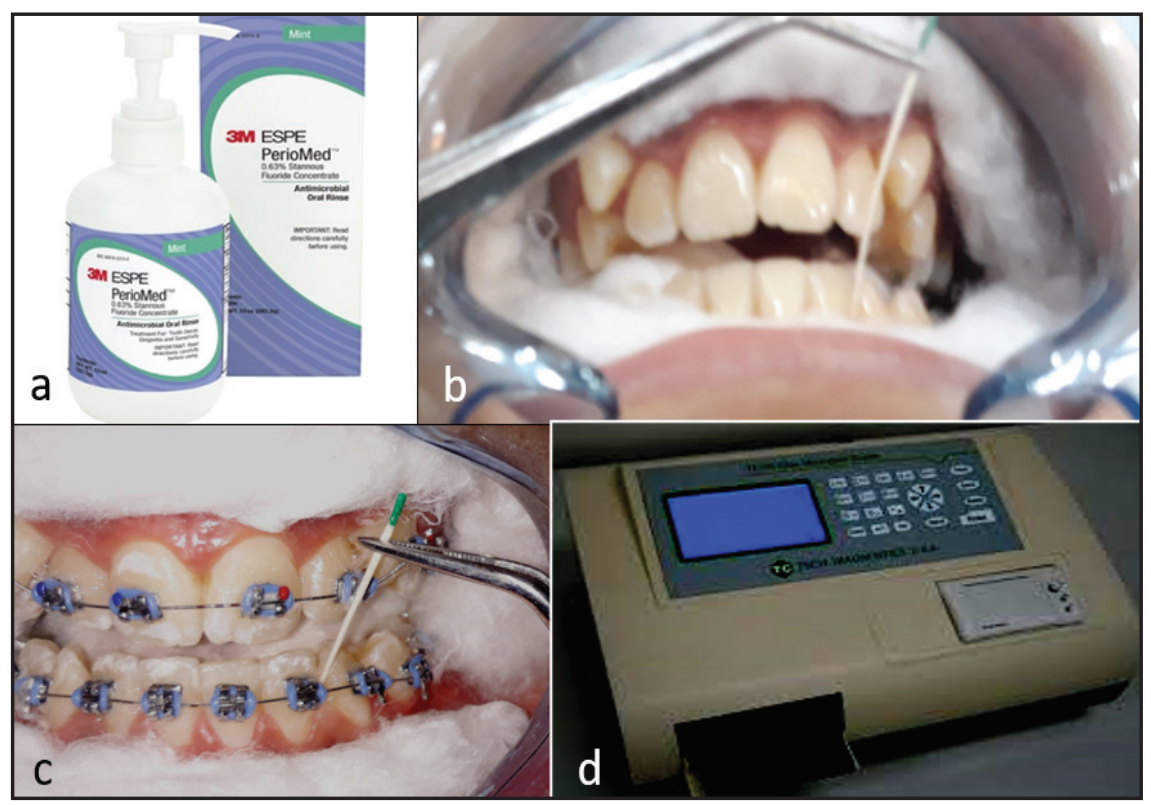

Figure (1): a; Periomed mouth wash, b; gingival crevicular fluid samples collection at baseline time, c; collection of GCF during orthodontic treatment, and $\mathrm{d}$; ELIZA reader. 


\section{RESULTS}

The statistical analysis showed the interleukin1beta level values were high at the onset of periodontal inflammation at the same range with no significant differences between the studied groups. Moreover, at the end of the study, group I and group II showed a marked decrease in the interleukin-1beta level compared to the control group, and there was a statistically non-significant difference between group I \& II. The statistical analysis showed bacterial count values were high at the onset of inflammation in all groups at the same range with no significant differences. Moreover, at the end of the study period after 28 days, group I and group II showed a marked decrease in the level of bacterial count compared to the control group and there was a statistically significant difference between group I\&II.
The statistical analysis of the clinical parameters at the initiation of orthodontic activation with fixed appliances showed the probing depth was high at all groups while after treatment using a fluoride mouthwash, the group I recorded the lowest scores among the other studied groups. The control group had the highest mean scores and no significant differences between the other two tested groups. The plaque index measurement was high at all groups at the onset of periodontal inflammations and after treatment group I \& group II recorded the lowest scores, while group III (control group) had the highest mean scores. Also, gingival index measurements were high at the onset of inflammation in all groups and after treatment shows the lowest scores in both the two tested groups and no significant difference between them.

Table (1): Comparison between the groups according to Interleukin 1- $\beta$, Aerobic Bacterial count $x 10^{3}$, and Anaerobic Bacterial count $\times 10^{3}$.

\begin{tabular}{|c|c|c|c|c|c|c|c|c|}
\hline & \multicolumn{2}{|c|}{ Group I } & \multicolumn{2}{|c|}{ Group II } & \multicolumn{2}{|c|}{ Group III } & \multirow[t]{2}{*}{$\mathbf{F}$} & \multirow[t]{2}{*}{$\mathbf{p}$} \\
\hline & Mean & \pm SD & Mean & \pm SD & Mean & \pm SD & & \\
\hline \multicolumn{9}{|l|}{ Interleukin 1- $\beta$} \\
\hline Baseline time & 608.6 & 75.6 & 594.4 & 60.9 & 588.2 & 116.9 & 0.1514 & 0.8602 \\
\hline 1 week & 1185.2 & 101.1 & 1159.7 & 154.1 & 1097.4 & 235.2 & 0.692 & 0.5092 \\
\hline 2 weeks & 860.3 & 89.8 & 939.8 & 110.1 & 948.3 & 172.0 & 1.417 & 0.2599 \\
\hline 4weeks & $614.6^{c}$ & 102.7 & $700.9^{b}$ & 99.9 & $797.2^{\mathrm{a}}$ & 108.0 & 7.766 & $0.0022 *$ \\
\hline \multicolumn{9}{|c|}{ Aerobic Bacterial count $\times 10^{3}$} \\
\hline Baseline time & $76.24 b$ & 19.04 & $99.02 \mathrm{~b}$ & 43.81 & $172.66 \mathrm{a}$ & 73.94 & 9.83 & $0.0006^{*}$ \\
\hline 1 week & $11.6 \mathrm{~b}$ & 5.25 & $173.5 \mathrm{a}$ & 53.70 & $193.44 \mathrm{a}$ & 88.60 & 27.73 & $<0.0001 *$ \\
\hline 2 weeks & $8.89 \mathrm{c}$ & 3.59 & $125.66 \mathrm{~b}$ & 43.19 & $232.69 a$ & 179.33 & 34.12 & $<0.0001 *$ \\
\hline 4weeks & $7.56 \mathrm{c}$ & 3.80 & $123.18 b$ & 50.05 & $312.6 \mathrm{a}$ & 199.2 & 38.35 & $<0.0001 *$ \\
\hline \multicolumn{9}{|c|}{ Anaerobic Bacterial count $\times 10^{3}$} \\
\hline Baseline time & $17.34 \mathrm{~b}$ & 8.42 & $38.61 \mathrm{~b}$ & 13.28 & $1636.6 \mathrm{a}$ & 608.5 & 69.85 & $<0.0001 *$ \\
\hline 1 week & $24.30 \mathrm{~b}$ & 8.04 & $57.96 \mathrm{~b}$ & 28.32 & $1766.7 \mathrm{a}$ & 763.27 & 55.12 & $<0.0001 *$ \\
\hline 2 weeks & $2.04 \mathrm{c}$ & 1.07 & $28.26 \mathrm{~b}$ & 11.88 & $1837.1 \mathrm{a}$ & 752.37 & 83.11 & $<0.0001 *$ \\
\hline 4weeks & $1.68 \mathrm{c}$ & 0.74 & $27.21 \mathrm{~b}$ & 11.93 & $1936.5 \mathrm{a}$ & 654.88 & 70.2 & $<0.0001 *$ \\
\hline
\end{tabular}

$p: p$ value for comparison between the groups 
Table (2): Comparison between the groups according to Probing pocket depth (mm), Gingival index, and Plaque index.

\begin{tabular}{|c|c|c|c|c|c|c|c|c|}
\hline & \multicolumn{2}{|c|}{ Group I } & \multicolumn{2}{|c|}{ Group II } & \multicolumn{2}{|c|}{ Group III } & \multirow[t]{2}{*}{$\mathbf{F}$} & \multirow[t]{2}{*}{$\mathbf{p}$} \\
\hline & Mean & \pm SD & Mean & \pm SD & Mean & \pm SD & & \\
\hline \multicolumn{9}{|c|}{ Probing pocket depth (mm) } \\
\hline Baseline time & $5.25^{b}$ & 1.96 & $5.25^{\mathrm{a}}$ & 3.19 & $6.63^{\mathrm{a}, \mathrm{b}}$ & 2.64 & 3.22 & 0.056 \\
\hline 1 week & $3.50^{\mathrm{b}}$ & 0.53 & $3.88^{\mathrm{a}, \mathrm{b}}$ & 0.95 & $4.75^{\mathrm{a}}$ & 0.71 & 5.82 & $0.009 *$ \\
\hline 2 weeks & $2.38^{\mathrm{c}}$ & 0.44 & $3.13^{\mathrm{b}, \mathrm{c}}$ & 0.95 & $3.88^{\mathrm{a}, \mathrm{b}}$ & 0.99 & 6.46 & $0.006^{*}$ \\
\hline 4weeks & 2.25 & 0.44 & 2.38 & 1.22 & 3.13 & 0.58 & 2.46 & 0.09 \\
\hline \multicolumn{9}{|l|}{ Gingival index } \\
\hline Baseline time & 2.5 & 0.5 & 2.4 & 0.5 & 2.63 & 0.52 & 0.46 & 0.637 \\
\hline 1 week & $1.6^{\mathrm{b}}$ & 0.4 & $2.1^{\mathrm{a}}$ & 0.5 & $2.38^{\mathrm{a}}$ & 0.52 & 5.3 & $0.0139 *$ \\
\hline 2 weeks & 1.4 & 0.5 & 1.63 & 0.4 & 1.9 & 0.52 & 2.27 & 0.128 \\
\hline 4weeks & $1.1^{\mathrm{b}}$ & 0.4 & $1.38^{\mathrm{b}}$ & 0.5 & $1.8^{\mathrm{a}}$ & 0.52 & 3.39 & $0.036^{*}$ \\
\hline \multicolumn{9}{|l|}{ Plaque index } \\
\hline Baseline time & 2.5 & 0.5 & 2.5 & 0.5 & 2.1 & 0.76 & 7.58 & 0.134 \\
\hline 1 week & 1.63 & 0.74 & 2.0 & 0.8 & 2.0 & 0.5 & 0 & 0.451 \\
\hline 2 weeks & 1.3 & 0.52 & 1.38 & 0.5 & 1.8 & 0.5 & 2.33 & 0.122 \\
\hline 4weeks & 1.1 & 0.52 & 1.38 & 0.5 & 1.6 & 0.4 & 2.27 & 0.128 \\
\hline
\end{tabular}

p: p-value for comparison between the groups

Table (3): Correlation between interleukin $\beta 1$ concentration and Bacterial count and clinical findings.

\begin{tabular}{|l|c|c|}
\hline \multirow{2}{*}{} & \multicolumn{2}{|c|}{ Interleukin $\beta$-1 } \\
\cline { 2 - 3 } & $\mathrm{r}$ & $\mathrm{p}$ \\
\hline Bacterial count & .254 & .426 \\
\hline Aerobic bacteria & $.805^{* *}$ & $.002^{*}$ \\
\hline Anaerobic bacteria & 0.0961 & 0.791 \\
\hline Clinical findings & 0.1572 & 0.664 \\
\hline Probing depth & 0.1042 & 0.774 \\
\hline Gingival index & \\
\hline Plaque index &
\end{tabular}

r: Pearson coefficient

*: Statistically significant at $p \leq 0.05$

\section{DISCUSSION}

The present study examined the effective use of two types of fluoride-containing mouthwashes (PERIOMED / LISTERINE® Mouthwash), compared with using the distilled water which has no antimicrobial action in patients treated with fixed orthodontic appliances, by assessing the level of interleukin1-beta and microbial count in the gingival crevicular fluid and measuring the following clinical parameters included Probing pocket depth, Plaque index and gingival index. The current study supports the use of gingival crevicular fluid for research to study periodontal health with orthodontic fixed appliances because it's a noninvasive nature method and can repetitive sampling from the same site. 
It has been shown that the local production of interleukin (IL)-1_ in the gingival crevicular fluid rises with the increase of inflammation ${ }^{(10,18)}$. Hence, IL-1_ is a reliable marker for the degree of gingival inflammation. The role of cytokines in inflamed periodontal tissues has been cited as being of major importance in periodontal disease progression. The results of this study showed that there were increase in IL-1 $\beta$ levels at the onset of periodontal inflammation after orthodontic treatment compared to the healthy periodontal tissue at base time (before treatment) in all groups, and the mean of IL-1 $\beta$ after one week of treatment was the highest mean. Similar findings were reported in a previous studies indicating that it may be involved in the inflammatory process ${ }^{(19,20)}$.

In the present study probing pocket depth, plaque index and gingival index, showed a higher level at baseline time before activation of the treatment in all groups. These findings were in agreement with ${ }^{(21)}$. Who found the teeth that received a chlorhexidinecontaining varnish showed significantly lower values in the follow-ups for most of the evaluated parameters (PD Band, PI Band, PI Bracket, GI Band, GI Bracket).

Regarding interleukin-1beta the results showed there was a weak correlation between interleukin1 beta concentration and assessed clinical parameters, which is associated with periodontal inflammation ${ }^{(22)}$. In this context, it has been shown recently that interleukin-1 beta level correlates significantly with inflammatory marker such as (IL-1), IL-6, and tumor necrosis factor- $\alpha$ (TNF- $\alpha$ ), appear to have a central role in periodontal inflammations. Further highlighting its role in chronic inflammation, increased level of IL-1 $\beta$ in (GCF) samples from chronic inflammation has been reported ${ }^{(22)}$. Low levels of IL-1 $\beta$ had been reported in normal serum. It is thought that IL-1 genes are induced to respond to tissue damage or an infection. Elevated levels had been reported in many infectious disease conditions and noninfectious inflammatory conditions such as periodontal disease $^{(19)}$.
To determine the profile response to periodontal therapy and the disease status (23) assessed longitudinally different salivary biomarkers of periodontitis. IL-1 $\beta$, IL-8, MIP-1 $\alpha$, MMP-8, OPG, and TNF- $\alpha$ salivary cytokine levels screened. Salivary levels of IL-1 $\beta$ reflected disease severity and response to therapy suggesting its potential utility for monitoring periodontal disease status. The results of the present study showed a decrease in the level of interleukin-1Beta level at GCF in both of the tested groups compared with the control group, the reason for these results were the antibacterial, antioxidant and anti-inflammatory properties ${ }^{(24,25)}$ of LISTERINE® Mouthwash $(0.02 \%$ sodium fluoride) and the ability of PERIOMED (0.63\% stannous fluoride) to prevent periodontitis ${ }^{(26)}$ which promotes long-lasting bacteriostatic and bactericidal properties which inhibit plaque and treat/prevent gingivitis ${ }^{(27,28)}$.

The results of the current study were also correlated with another study ${ }^{(21)}$. Who found the teeth that received a chlorhexidine-containing varnish showed significantly lower values in the follow-ups for most of the evaluated clinical parameters as well as the levels of IL-1beta reflected the higher impact gingival health. While non-significant changes were registered after the use of both active and placebo varnish applications in interleukin-1beta level was found by ${ }^{(29)}$ although there was a significant reduction of $\mathrm{PGE}_{2}, \mathrm{PGI}_{2}$, and $\mathrm{LTB}_{4}$ levels in GCF following the active varnish treatment when compared to baseline values.

In the present study the routine use of the two types of mouthwash in the tested groups generated beneficial effects on periodontal health. PERIOMED (0.63\% stannous fluoride), LISTERINE® $(0.02 \%$ sodium fluoride) mouthwashes showed there was a statistically significant reduction in PPD compared to the control group. Concerning the probing pocket depth the results of PERIOMED group revealed a statistically significant reduction in PPD following the regular use of mouthwash. Also in a previous study ${ }^{(30)}$ concluded that the observed probing depth 
reduction could be attributed to the broad-spectrum antimicrobial effect of stabilized stannous fluoride dentifrice on periodontal pathogens.

These findings were in accordance with previous study ${ }^{(31)}$. They conducted that the use of $\mathrm{SnF} 2$ products results in reducing clinical parameters and gingivitis. Moreover, in another a randomized clinical study ${ }^{(32)}$ they found direct irrigation of the entire pocket or sulcus filled with stannous fluoride solution, no scaling or other treatment procedure was performed. They concluded that stannous fluoride appears highly effective in reduction of pocket depth throw its potential antimicrobial effect.

Listerine ${ }^{\circledR}$ also promoted a statistically significant reduction in PPD compared with the control group, the antimicrobial effect achieved in this group contributed to sodium fluoride supplements in mouthwash and their physiological properties. In this regarded Listerine green tea mouthwash contains sodium fluoride which is an anti-inflammatory agent ${ }^{(26)}$. These findings were in accordance with another study ${ }^{(33)}$. They reported that the usage of Listerine Green tea mouth-rinse as an adjunct to regular mechanical oral hygiene measures seems to be beneficial in the treatment of gingivitis patients.

In comparison with results of the present study, a prospective randomized, double-blind study ${ }^{(14)}$ who investigated the antibacterial and anti-inflammatory effect of amine fluoride/stannous fluoride and sodium fluoride $(\mathrm{NaF})$ on the development of white spot lesions, plaque, and gingivitis on maxillary anterior teeth in orthodontic treated patients. They concluded that the combined use of an $\mathrm{AmF} /$ $\mathrm{SnF}_{2}$ toothpaste/ mouth rinse had a slightly more inhibitory effect on white spot lesion development, plaque and gingivitis on maxillary anterior teeth during fixed orthodontic treatment compared with sodium fluoride group. In contrary to the results of the present study another study ${ }^{(34)}$ found there were no observed differences in the $\mathrm{SnF}_{2}$ or $\mathrm{NaF}$ groups when compared with the placebo group at 18 months study period.
Regarding Plaque Index the relationship between orthodontic procedures and periodontal status is considered a challenge. Plaque accumulates around the orthodontic appliance, causing gingivitis; decalcification, caries, and inflammatory periodontal disease are some of the commonly recognized consequences of the failure to maintain good oral hygiene, especially during orthodontic treatment ${ }^{(35)}$. Periodontal maintenance programs must be carried out in conjunction to orthodontic treatment and also after completion of therapy ${ }^{(36-38)}$.

The results of this study showed a statistically significant great reduction in plaque index in PERIOMED stannous fluoride group compared with the control group when the regular use of fluoride-free toothpaste and rinse with distilled water is done. The results were in agreement with the results of a previous study ${ }^{(30)}$ that showed a significant reduction in plaque formation when compared to a negative control dentifrice.

Collectively, the present study results in conjunction with previously reported long-term clinical studies support that the anti-plaque/anti-gingivitis therapeutic benefits and the underlying mechanism of action of this agent. In contrary to the result, another study ${ }^{(10)}$ who investigated whether conventional tooth brushing and twice-daily use of a brush with stannous fluoride $(\mathrm{SnF} 2)$ gel would be more effective for controlling plaque accumulation in the presence of orthodontic appliances than conventional toothbrushing alone. They observed that the SnF2 gel group had statistically significant lower scores for plaque index than did the control group. The authors concluded that the use of $\mathrm{SnF} 2$ gel is an effective adjunct to mechanical tooth cleaning in adolescents undergoing orthodontic treatment with fixed appliances.

The results of Listerine mouthwash showed a statistically significant reduction in dental plaque accumulation on the tooth surface, these findings were in agreement with a previous study ${ }^{(39)}$ who compare the efficacy of chlorhexidine and sodium 
fluoride mouthwashes in the reduction of plaque deposition. They found there was significant reduction in plaque in both test groups and the efficacy of both mouthwashes was statistically equal. They concluded that sodium fluoride is a potent antimicrobial agent and would be better mouthwash due to its additional remineralization property for the prevention of dental caries and gingivitis. However, another study ${ }^{(33)}$ reported that the usage of mouth-rinse as an adjunct to regular mechanical plaque control practice and professional scaling. At the end of the study, Gingival Index showed a statistically significant reduction in the tow tested groups compared with the control group. Moreover there was a significant reduction in gingival index in PERIOMED mouthwash group due to the presence of stannous fluoride in the mouthwash as the main ingredient. Stannous fluoride has a potent antiinflammatory effect.

These results were in accordance with a previous studies ${ }^{(30)}$ and ${ }^{(32)}$ they founds a statistically significant reductions in gingival bleeding and gingivitis when compared with a negative control dentifrice. Stannous fluoride was a broad-spectrum anti-microbial agent that has been used in dentistry as a chemical adjunct to prevent dental caries and gingivitis.

On the other hand other study ${ }^{(40)}$ found that the SnF2 gel group had significantly lower scores for gingival index, and bleeding tendency at all examinations than did the control group. Also in the SnF2 group, one subject developed mild coronal staining, and two subjects developed moderate staining.

Another study ${ }^{(35)}$ was detected more stain in the $\mathrm{SnF}_{2}$ group than in the other two groups at all periods except at baseline. However, no differences were observed in gingival bleeding index and gingivitis in the $\mathrm{SnF}_{2}$ when compared with the placebo group at 18 months. Besides the Listerine mouthwash containing sodium fluoride products tested in this trial contained several different constituents with putative anti-inflammatory and anti-bacterial which theoretically could be useful in controlling plaque, gingivitis, and periodontal disease. The result of this group showed an obvious decrease in GI through the experiment.

Results of other clinical studies had confirmed the long- term and gingival bleeding reduction properties of sodium fluoride dentifrices. Although the results of a previous study ${ }^{(35)}$ showed that the indicated $\mathrm{NaF}$ is no more effective than a placebo in reducing gingival bleeding index and gingivitis. Finally, this study was carried out to evaluate the effect of two types of mouth-rinse on periodontal health in orthodontic patients. The results of the present study showed an improvement in the signs of periodontal inflammation following the regular use of fluoridated mouthwash and oral hygiene instructions.

\section{Correlation between biochemical and microbio- logical finding:}

The present study showed an overall strong positive correlation between Interleukin- $1 \beta$ concentration and anaerobic bacterial count in the experimental groups and control group and between base time and other different periods. These correlations were highly significant among all studied groups. These findings were in agreement with a study reported by a previous study ${ }^{(41)}$ they investigated the microbiologic and immunologic factors related to orthodontic treatment-induced gingival enlargement periodontal therapy was given to the GE group, and all parameters were reassessed after 4 weeks. They found that after periodontal therapy, the gingival enlargement group showed significant improvements in the clinical parameters associated with significant reductions in bacterial count. The levels of IL-1 $\beta$ decreased significantly compared with the baseline associated with the improvement of periodontal variables. They concluded periodontal pathogens might have a relationship with the initiation and development of orthodontic treatment-induced gingival enlargement. Inflammatory cytokines (IL$1 \beta)$ can also be considered as contributing factors. However; low levels of IL-1 $\beta$ have been reported 
in normal serum. It is thought that IL-1 genes are induced to respond to tissue damage or an infection. Elevated levels have been reported in many infectious disease conditions and noninfectious inflammatory conditions such as periodontal disease. In addition to elevated serum levels, IL-1 has been found in synovial fluids of patients with rheumatoid arthritis and cerebrospinal fluid after neurological inflammation or insult. At the other end of the spectrum, low levels of IL-1 have been found in malnutrition and advanced neoplasia suggesting perhaps a complex immunological and physiological regulatory role for this cytokine. ${ }^{(19)}$

These results were in accordance with another study ${ }^{(42)}$ who reported the role of genetic polymorphism in determining the quantity of IL-1b produced and also the contributory role of other cytokines that share similar biologic activity. In conclusion they support the concept that if IL-1b is to be used as a marker of inflammatory periodontal disease the IL-1 genotype must also be detected.

\section{Correlation between interleukin- 1beta and clinical parameters:}

The present study showed a weak correlation between clinical parameters and the level of IL-1 $\beta$. As these differences are minimal and not statistically significant it can be assumed that PPD, PI, and GI have not influenced the GCF IL-1 $\beta$ activity. These findings were in agreement with a previous study ${ }^{(24)}$ who investigates the possible correlation between interleukin-1 $\beta$ immunologic mediators and gingival clinical parameters in chronic and aggressive periodontitis. They concluded there were no correlations between cytokine concentrations and clinical parameters. These findings were in accordance with many clinical another studies reported the use of IL-1 $\beta$ present in saliva or gingival crevicular fluid as a potential biomarker of periodontal disease and they were correlated with individual clinical parameters indicative of periodontal disease. ${ }^{(21,42,43)}$

\section{CONCLUSION}

The level of interleukin -1beta in gingival crevicular fluid is a useful biomarker to detect periodontal health related to fixed orthodontic treatment. Fluoridated mouthwashes containing (stannous fluoride as well as sodium fluoride) have an anti-inflammatory effect and enhanced the periodontal health status. Both of the tested groups which used fluoridated mouthwashes had a positive impact on the level of IL-1 $\beta$. Stannous fluoride mouthwash showed the best results in the level of IL- $1 \beta$, since in the reduction of the bacterial count it also includes improving in the clinical parameters (PD, PI, GI) compared with the other samples of the study.

\section{REFERENCES}

1. Sukontapatipark W,El-Agroudi MA, Selliseth NJ, Thunold $\mathrm{K}$, Selvig KA . Bacterial colonization associated with fixed orthodontic appliances: a scanning electron microscopy study. Eur J Orthod. 2001; 23: 475- 84.

2. Diamanti KA, Gusberti FA, Lang NP. Clinical and microbiological effects of fixed orthodontic appliances. J Clin Period. 1987; 14: 326- 33.

3. Wennstrom JL. Mucogingival considerations in orthodontic treatment. Semin Orthod. 1996; 2: 46- 54.

4. Bollen AM, Cunha - Cruz J, Bakko DW , Huang GJ,Hujoel PP. The effect of orthodontic theraby on periodontal health: a systematic review of controlled evidence .J Am Dent Assoc. 2008; 139: 413- 22.

5. Axelsson P, Lindhe J. Effect of controlled oral hygiene procedures on caries and periodontal disease in adults results after 6 years, J Clin Period. 1981; 8: 239- 48.

6. DePaola LG, Overholser CD, Meiller TF, Minah GE, Niehaus C. Chemotherapeutic inhibition of supra gingival dental plaque and gingivitis development. J Clin Period. 1989; 16: 311-15.

7. Clocheret K and Willems G. Idiopathic gingival hyperplasia and orthodontic treatment: a case report .J Orthod. 2003; 30: $13-9$.

8. Huser MC, Baehni PC, Lang R. Effects of orthodontic bands on microbiologic and clinical parameters. Am J Orthod Dentofa. Orthop. 1990; 97: 213- 8. 
9. Paolantonio M, Festa F, di PG, D'Attilio M, Catamo G, Piccolomini R. Site-specific subgingival colonization by Actinobacillus actinomycetemcomitans in orthodontic patiants. Am J Orthod Dentofa. Orthop. 1999; 115: 423- 8.

10. Orozco A, Gemmell E, Bickel M, Seymour GJ. Interleuken1 beta, interleukin-12 and interleukin-18 levels in gingival fluid and serum of patients with gingivitis and periodontitis. Oral Microbiol Immunol. 2006; 21: 256- 60 .

11. Okada H, Murakami S. Cytokine expression in periodontal health and disease. Crit Rev Oral Biol Med. 1998; 9: 248- 66

12. Rawlinson A, Dalati MH, Rahman S, Walsh TF, Fairclough AL. Interleukin-1 and IL-1 receptor antagonist in gingival crevicular fluid. J Clin Period. 2000; 27: 738- 43.

13. AL-Quanaian TA. The effect of whitening agents on caries susceptibility of human enamel .Oper. Dent. 2005; 30: 265- 70 .

14. Qgaard B: A prospective randomized clinical study on the effects of amine fluoride/ stannous fluoride toothpaste / mouthrinse on plaque, gingival and initial caries lesion development in orthodontic patients. Eur J Orthod. 2006; 28: 8- 12.

15. Warrick JM, Miller LL, Doan EJ, Stookey GK. Cariespreventive effects of sodium and amine fluoride dentifrices. American J Dent. 1999; 12: 9- 13.

16. Baehni PC, Takeuci Y: Anti - plaque agents in the prevention of biofilm - associated oral diseases. Review. Oral diseases, 2003; 9:23-29.

17. Abramson JH. The Cornell Medical Index as an epidemiological tool. Am J Public Health Nations Health. 1966; 56 : 287-98.

18. Rawlinson A, Dalati MH, Rahman S, Walsh TF, Fairclough AL. Interleukin-1 and IL-1 receptor antagonist in gingival crevicular fluid. J Clin Periodontol.2000; 27: 738- 43.

19. Waschul B, Herforth A, Stiller WR, Idel H, Granrath N, Deinzer R. Effects of plaque, psychological stress and gender on crevicular IL-1beta and IL-1ra secretion. J Clin Periodontol 2003; 30: 238- 4.

20. Barksby HE, Lea SR, Preshaw PM, Taylor JJ. The expanding family of interleukin-1 cytokines and their role in destructive inflammatory disorders. Clin Exp Immunol 2007; 149: $217-25$

21. Ekaterini P, Limbach M, Teichmann M, Karin C. Folwaczny M, Hickel R, et al. Orthodontic Attachments and Chlorhexidine-Containing Varnish Effects on Gingival Health. Angle Orthod 2008, 78: 908-16.
22. Vahabi S, Sattari M, Taheraslani M, Bagheban A. Correlation between Interleukin-1 $\beta$, Interleukin-6 and Tumor Necrosis Factor- $\alpha$ and Clinical Parameters in Chronic and Aggressive Periodontal Disease. J Periodontol Implant Dent 2011; 3: 51- 6 .

23. Sexton WM, Lin Y, Kryscio RJ, Dawson DR, Ebersole JL, Miller CS. Salivary biomarkers of periodontal disease in response to treatment. J Clin Periodontol. 2011; 38: 434- 41.

24. Allaker RP, Douglas CI. Novel anti-microbial therapies for dental plaque related diseases. Int J Antimicrob Agents 2009; 33(1):8-13.

25. Chikte UM, Lewis HA, Rudolph M J. The effectiveness of a school based fluoride mouthrinse programme. J Dent Assoc S Afr. 1996; 51: 697- 700.

26. Groeneveld A, Purdell DJ, Arends J. Remineralization of artificial caries lesions by stannous fluoride. Caries Res. 1976; 10:189- 200.

27. Otten MP, Busscher HJ, Abbas F, van der Mei HC, van Hoogmoed CG. Plaque-left-behind after brushing: intraoral reservoir for antibacterial toothpaste ingredients. Clin Oral Investig 2012; 16: 1435- 42.

28. Ramji N, Baig A, Lawless MA, Saletta L, Meister E, Coggan J. Sustained antibacterial actions of a new stabilized stannous fluoride dentifrice containing sodium hexameta-phosphate. Compend Contin Educ Dent 2005; 26:19- 38 .

29. Yucel LT, Twetman S, Skold LK, Modeer T. Effect of an antibacterial dental varnish on the levels of prostanoids, leukotriene B4, and interleukin-1 beta in gingival crevicular fluid. Acta Odontol Scand. 1999; 57: 23- 7.

30. Mankodi S, Bartizek RD, Winston JL, Biesbrock AR, McClanahan SF, He T. Antigingivitis efficacy of a stabilized $0.454 \%$ stannous fluoride/sodium hexameta-phosphate dentifrice. J Clin Peridontol 2005; 32: 75-80.

31. Paraskevas S, van der Weijden GA. Review of the effects of stannous fluoride on gingivitis. J Clin Periodontol 2006; 33: $1-3$.

32. Mazza JE, Newman MG, Sims TN. Clinical and antimicrobial effect of stannous fluoride on periodontitis, J Clin Periodontol. 1981; 8: 203- 12.

33. Shriparna B, Rithesh K, Savita S, Shivaprasad B. Comparative evaluation of the effect of Green tea, Listerine and Chlorhexidine mouthwashes in gingivitis patients: A randomized controlled trial Sch. J. Dent Sci. 2015; 2: 104- 12 
34. Larry F, Bruce L, Bakdash B, Dorothee M, Aeppliph D, Carl L, Effect of tooth brushing with $0.4 \%$ stannous fluoride and $0.22 \%$ sodium fluoride gel on gingivitis for 18 months. J A Dent Assoc.1989; 119 : 283-9

35. Bloom RH, Brown LR. The effect of orthodontic appliance on the oral microbial flora. Oral Surg. 1964; 17: 658-76.

36. Sanganash FG, Siddharth R, Sachin S. Periodontal Maintenance program in Orthodontic Patients. International J of Scien. 2013; 2:65-71.

37. Boyd R. Periodontal implications of orthodontic treatment in adults with reduced or normal periodontal tissues versus those of adolescents. Am J Orthod DentoFac Orthop, 1989; 96:191- 9 .

38. Boyd RL, Rose CM: Effect of rotary electric tooth brush versus manual tooth brush on decalcification during orthodontic treatment. Am J Orthod DentoFac Orthop. 1994; 105: 450-6.
39. Sundas S, RAO A. Comparative Evaluation of Effect of Chlorhexidine and Sodium Fluoride Mouthwashes on Plaque. J Nepal Health Res Coun, 2015; 13: 133- 7

40. Boyd RL, Chun YS, Eighteen-month evaluation of the effects of a $0.4 \%$ stannous fluoride gel on gingivitis in orthodontic patients. Am J of Orthod and Dentofac Orthop. 1994; 105: 35- 41

41. Gong Y, Jing Lu, and Dingc X. Clinical, microbiologic, and immunologic factors of orthodontic treatment-induced gingival enlargement Am J Orthod Dentofac Orthop 2011;140: 58-64.

42. Faizuddin M, Bharathi SH, Rohini NV. Estimation of interleukin-1b levels in the gingival crevicular fluid in health and in inflammatory periodontal disease. J Periodont Res $2003 ; 38: 111-4$.

43. Miller CS, King CP, Langub MC, Kryscio RJ, Thomas MV. Salivary biomarkers of existing periodontal disease: a cross-sectional study. J Am Dent Assoc. 2006; 137: 322- 9. 